\title{
THE EFFECTS OF TEMPERATURE ON THE DORMANCY AND GERMINATION OF CIRSIUM ARVENSE (L.) SCOP. SEEDS
}

\author{
ANNA BOCHENEK ${ }^{1}$, JANUSZ GOŁASZEWSKI ${ }^{2}$, \\ AgNIESZKA I. PIOTROWICZ-CIEŚLAK ${ }^{1}$, RYSZARD J. GÓRECKI ${ }^{1}$ \\ ${ }^{1}$ Department of Plant Physiology and Biotechnology, \\ University of Warmia and Mazury \\ Oczapowskiego 1A, 10-719 Olsztyn, Poland \\ e-mail: anna.bochenek@uwm.edu.pl \\ 2 Department of Plant Breeding and Seed Production, \\ University of Warmia and Mazury \\ Pl. Lódzki 3, 10-724 Olsztyn, Poland
}

(Received: March 2, 2009. Accepted: May 8, 2009)

\begin{abstract}
The ecophysiological regulation of seed dormancy in perennial species and those with a varied life cycle has not been studied in detail yet. That is why an attempt has been made to determine the Cirsium arvense seed water relations during stratification and afterripening at different temperatures and germination at constant or fluctuating temperatures on the basis of the hydrotime model. The obtained results showed that breaking of the primary dormancy of achenes took place only during the first stratification month at moderate temperatures, mainly due to an increase in the average water-stress tolerance in a seed population. The induction of secondary seed dormancy during after-ripening at all temperatures resulted mostly from a substantial loss of the seeds' ability to tolerate water stress. Fluctuating temperatures affected neither seed germination nor the hydrotime model parameters. The analysis of the variations of hydrotime model parameters allows a better understanding of the physiological basis of seed dormancy relief and induction.
\end{abstract}

KEY WORDS: afterripening, Cirsium arvense, dormancy, germination, hydrotime, stratification, weed seeds.

\section{INTRODUCTION}

Cirsium arvense (L.) Scop. is one of the major perennial and troublesome weeds of pasture, arable and ruderal areas in the temperate zone (Kumar and Irvine 1971; Donald 1990; Edwards et al. 2000). Being one of the world's worst weeds and the third most abundant weed species in Europe, it is particularly difficult to control (Skinner et al. 2000; Friedli and Bacher 2001). Infestation with $C$. arvense is an increasing problem especially in organic farming. Vegetative spread by roots and stems buried in soil is considered the main cause of its weediness, but creeping thistle can also effectively reproduce by sexual means. Populations of $C$. arvense exhibit a very wide range of clonal diversity, which indicates that sexual reproduction is very common (Heimann and Cussans 1996; Jump et al. 2003, Hettwer and Gerowitt 2004). Achene (further called seed) spread probably plays an important role in the infestation of new fields previously free of $C$. arvense. Biological control of creeping thistle using the plant pathogenic fungus or herbi- vores and mechanical or cultural strategies are increasingly being considered as an alternative to chemical control $(\mathrm{Gu}-$ ske et al. 2004; Bourdôt et al. 2006; Graglia et al. 2006). However, due to the fact that seeds are of great importance in the spread of this species, detailed knowledge of their ecophysiology could play a considerable role in the development of new biological control methods.

Earlier studies showed that Cirsium arvense seeds germinate in relatively high temperatures. The optimal germination temperature for Polish and British populations was $26^{\circ} \mathrm{C}$ and $30-35^{\circ} \mathrm{C}$, respectively. Pre-chilling released seed dormancy (Kumar et al. 1971; Bochenek and Giełwanowska 2006). Creeping thistle seeds did not show any apparent endogenous seasonal dormancy pattern. Environmental conditions in the soil bank resulted in the appearance of seasonal changes in seed germination. The dormancy breaking of imbibed seeds stored for 2 months at $19^{\circ} \mathrm{C}$ was complete, but during longer storage periods dormancy development occurred. The seed dormancy relief at lower temperatures was slower and incomplete. Nitrate, desicca- 
tion and light effects on seed germination were season-related (Bochenek and Giełwanowska 2006).

An important approach to describing germination in relation to accessible water is to analyze germination rates at different water potentials in a seed population on the basis of the hydrotime model. This model has explained the impact of different treatments on the seed dormancy and germination in numerous species (Bradford 1990; Bradford and Somasco 1994; Dutta and Bradford 1994; Batlla and Benech-Arnold 2004; Larsen et al. 2004; Toselli and Casenave 2002, 2005; Wang et al. 2005; Bochenek et al. 2007; Żuk-Gołaszewska et al. 2007). The hydrotime model, initially proposed by Gummerson (1986) and developed by Bradford (1990, 1994), describes the relation between the germination rate of given percentage $g\left(G R_{g}\right)$ and the value of the difference between the seed water potential $(\psi)$ and the physiological base water potential for primary root emergence $\left(\psi_{b}\right)$. The hydrotime model is of the form:

$$
\begin{aligned}
& \theta_{H}=\left(\psi-\psi_{b}(g)\right) \cdot t_{g} \\
& G R_{g}=1 / t_{g}=\left(\psi-\psi_{b}(g)\right) / \theta_{H}
\end{aligned}
$$

where $\theta_{H}$ is the hydrotime considered constant in a seed population, $\psi$ is the seed water potential, $t_{g}$ is the germination time for a specific fraction $g$, and $\psi_{b}(g)$ is the base or threshold water potential for germination of a specific fraction $g$. The model assumes that $\psi_{b}$ differs among fractions of a seed population. The values of $\psi_{b}$ are close to normal distribution which can be characterized by its mean, $\psi_{b}(50)$ and standard deviation, $\sigma_{\psi b}$ (Bradford 1995, 1996, 2002).

The goal of the study was to determine the Cirsium arvense seed water relations after stratification and afterripening at different temperatures and during germination at constant or fluctuating temperatures on the basis of the hydrotime model.

\section{MATERIALS AND METHODS}

Mature seeds of Cirsium arvense were collected from arable weedy fields in the vicinity of Olsztyn on 2-5th August 2006. After collection, the seeds were manually cleaned to remove perianths and kept for 2 days inside paper bags at $3{ }^{\circ} \mathrm{C}$ until the beginning of the experiments. Directly after harvest the seeds contained $12 \%$ of water. The seed lots were divided into 25 portions. Twelve of them were packed separately in fine mesh nylon envelopes. Each envelope with seeds was buried in wet light loam in a closed plastic pot and stored at $5,12,19$ or $26^{\circ} \mathrm{C}$ for 150 days. The water content of the stratified seeds was $48.5 \%$ on average. The other 12 seed portions were packed separately in

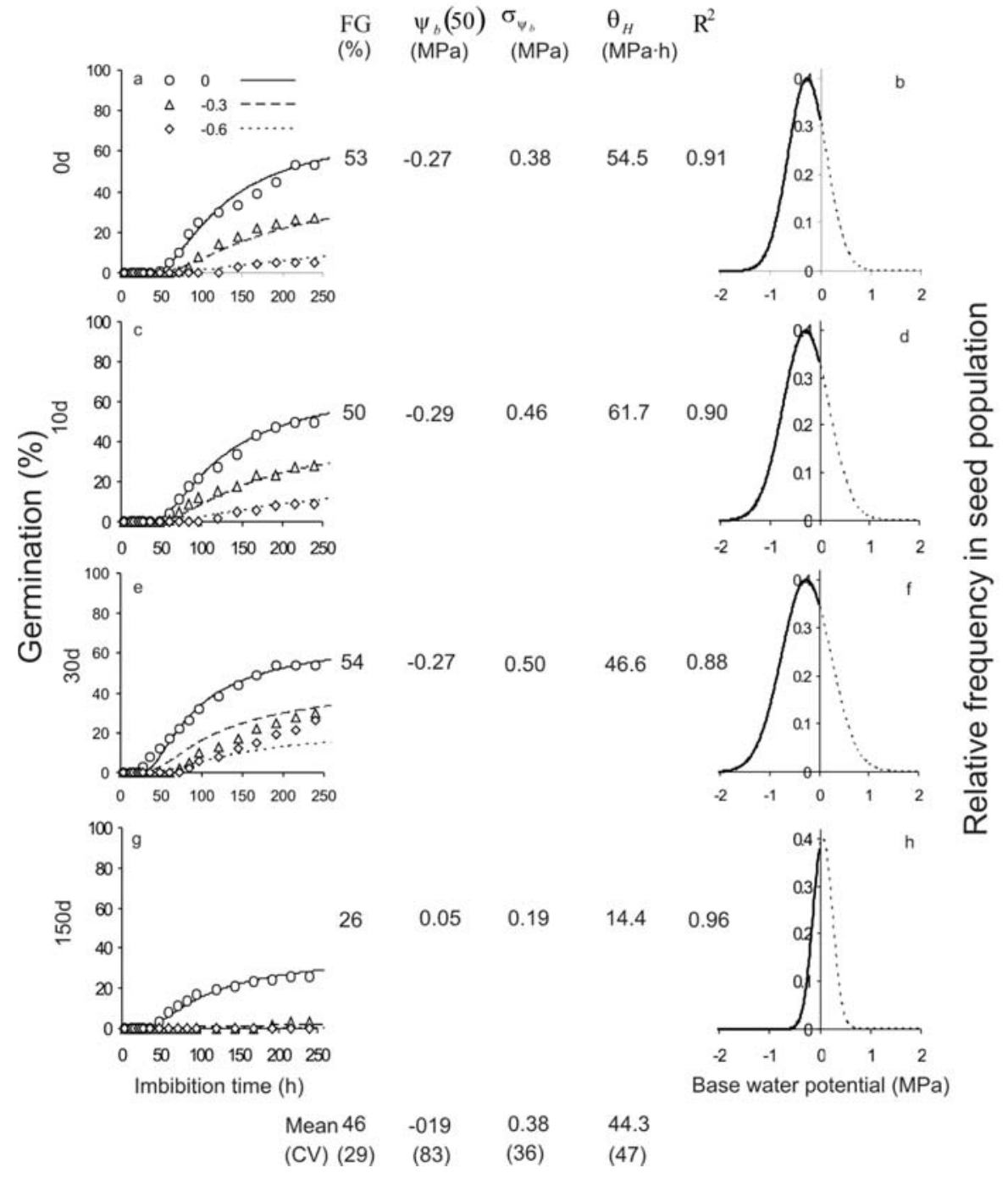

Fig. 1. Germination time courses of Cirsium arvense seeds after burial of $0,10,30$ and 150 days in $5^{\circ} \mathrm{C} . \mathrm{a}, \mathrm{c}, \mathrm{e}, \mathrm{g}-$ germination time courses of seeds at 0 (circles), -0.3 (triangles) and - 0.6 (rhombuses) MPa. $\mathrm{b}, \mathrm{d}, \mathrm{f}, \mathrm{h}-$ normal distribution showing the relative frequencies of $\psi_{b}(50)$ values of seeds. FG - final germination in water, $\psi_{b}(50)$ - mean base water potential, $\sigma_{\psi b}$ - standard deviation of base water potential, $\theta_{H}$ - hydrotime constant, CV - coefficient of variation, $\mathrm{R}^{2}-\mathrm{co}-$ efficient of determination of probit regressions. 


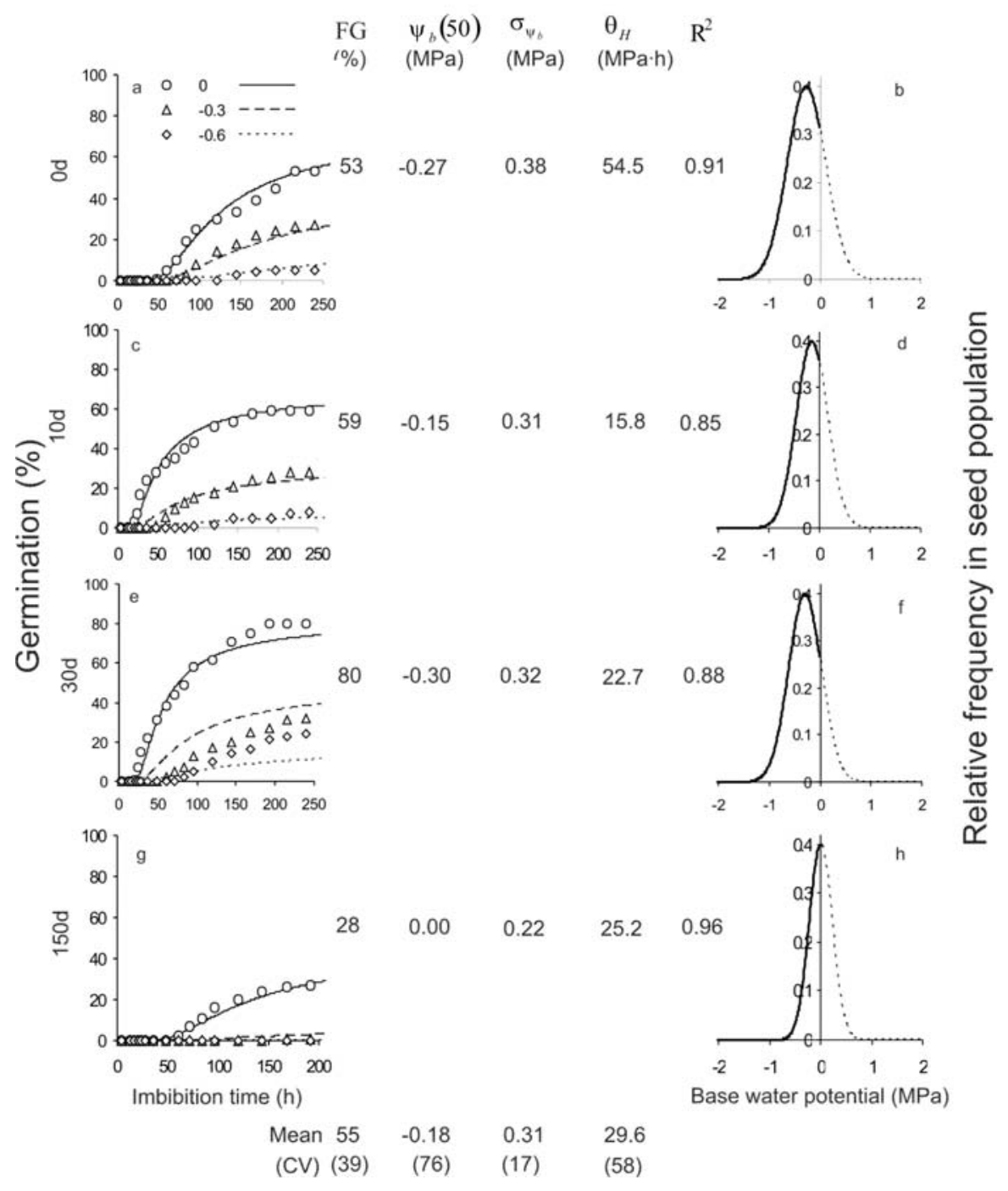

Fig. 2. Germination time courses of Cirsium arvense seeds after burial of $0,10,30$ and 150 days in $12^{\circ} \mathrm{C}$. The symbols, lines and letters as Figure 1. paper bags and stored at $12,19,26$ or $33^{\circ} \mathrm{C}$ for 150 days. During afterripening, the water content of the seeds was $6 \%$ on average. The 25 th portion was a control one. Before the experiment and after 10, 30 and 150 days' storage, seeds representing each temperature and experimental variant were tested for germination at water and reduced water potentials $(0,-0.3$ and $-0.6 \mathrm{MPa})$, which were determined utilizing water or polyethylene glycol (PEG 8000) solutions prepared according to Michel (1983). A vapour pressure osmometer (Model VAPRO 5520, Wescor Inc., USA) calibrated against $\mathrm{NaCl}$ solutions was applied to check the obtained $\psi$. Germination tests were performed in glass $9 \mathrm{~cm}$ Petri dishes (four replications of 25 seeds), following 0.5 $\mathrm{h}$ exposure to red light with a photon flux of $2.3 \mathrm{uM} \mathrm{m}^{-2} \mathrm{~s}^{-1}$ (six red fluorescent lamps, Philips 18W/15, 620-700 nm, max. emission about $660 \mathrm{~nm}$ ), on filter paper moistened with $5 \mathrm{ml}$ of water or PEG solution of indicated $\psi$. The dishes were placed in plastic bags to prevent evaporation and were subsequently incubated in low-temperature incubators at a constant temperature of $26^{\circ} \mathrm{C}$, for 8 days, in the dark, except for brief periods when germination was scored under green light (1 green fluorescent tube Philips TLD $\left.18 \mathrm{~W} / 865,2.2 \mathrm{uM} \mathrm{m}^{-2} \mathrm{~s}^{-1}\right)$. Germination was recorded at 4 , 12 or $24 \mathrm{~h}$ intervals, depending on germination rate. Ungerminated seeds were transferred to fresh solutions at 48-h intervals to maintain constant $\psi$ in the dishes. The germination criterion was a visible radicle protrusion. Ungerminated seeds were considered viable when they were firm after being squeezed with forceps. Tetrazolium tests had confirmed that firm embryos were viable but soft ones were not. Data were transformed to germination percentages based on viable seeds, and means were calculated. Seed germination time courses in water and osmotic solutions were analyzed by probit regression according to the population-based hydrotime model (Eqs 1,2) and the computational procedure proposed by Bradford $(1990,1995)$ and Gołaszewski and Bochenek (2008):

$$
\operatorname{probit}_{(g)}=\left[\psi-\left(\theta_{H} / t_{g}\right)-\left(\psi_{b}(50)\right] /\right) / \sigma_{\psi b}
$$

This procedure allowed the calculation of seed population hydrotime parameters, $\theta_{H}, \psi_{b}(50)$ and $\sigma_{\psi b}$ and enabled the germination courses predicted for the model to be obtained. Additionally, 14 days after harvest, germination of seeds was tested in constant $\left(26^{\circ} \mathrm{C}\right)$ and fluctuating $\left(19 / 33^{\circ} \mathrm{C}, 12 / 12 \mathrm{~h}\right)$ temperatures. PEG solutions were prepared adequately to each temperature. For incubation at a fluctuating temperature, the solution obtained for the average temperature was used. The remaining conditions of germination tests and calculations were as above. 


\section{RESULTS}

\section{Stratification}

Fifty-three per cent of creeping thistle seeds germinated directly after harvest. The stratification at $5^{\circ} \mathrm{C}$ did not cause any visible changes in germination or hydrotime model parameters. Only after 150 days, germination decreased by half, the value of the mean base water potential increased considerably and the values of $\sigma_{\psi b}$ and $\theta_{H}$ were clearly lowered (Fig. 1). Germination of more than $80 \%$ of imbibed seeds stored at $12^{\circ} \mathrm{C}$ for 30 days and at $19^{\circ} \mathrm{C}$ for 10 days was mainly due to a decrease in the hydrotime constant value. Longer exposure to such temperatures resulted in a dramatic fall in germination and an increase of $\psi_{b}(50)$ (Figs 2 and 3). At a high temperature stratification led to a gradual germination decrease (after 10 days as a result of the increased value of the mean base water potential, and after 30 days, increased values of $\theta_{H}$ and $\sigma_{\psi b}$ ). After a very long stratification period, germination decreased slightly. However, the model parameters changed: the value of $\psi_{b}(50)$ was above 0 , and the value of the remaining parameters significantly decreased. During stratification at all the temperatures, the biggest changes were observed in the mean base water potential (CV 76-150\%), while the smallest in the distribution of this parameter in the population (CV 10-62\%). The fit of experimental data for wet stored seeds at various temperatures was very good with $\mathrm{R}^{2}$ ranging from 0.85 to 0.99 , so the model parameters can be used to compare the effect of the treatment on seed dormancy regulation (Figs 1-4).

\section{Afterripening}

Dry stored Cirsium arvense seeds gradually decreased their germination at all the temperatures. After 150 days 4 $-7 \%$ of the seeds germinated (Figs 5-8). This considerable fall in germination resulted from the big increase in the mean base water potential, whose value was clearly positive after long afterripening at all the temperatures (CV 112$150 \%)$. The biggest changes in $\psi_{b}(50)$ were observed at $19^{\circ} \mathrm{C}$ (Fig. 6). The values of the other model parameters also increased, but to a much lower extent. In most cases, the model fitted very well with the experimental data with values of $\mathrm{R}^{2}$ from 0.91 to 0.99 (Figs 5-8).

\section{Fluctuating temperatures}

A two-week dry storage of seeds at $3^{\circ} \mathrm{C}$ caused a slight germination increase of creeping thistle seeds, which above all resulted from a visible shift of the base water potential distribution to the left. On the other hand, the values of the other parameters were enhanced. Seed germination at a constant optimal temperature, which constituted the mean of extreme fluctuation temperatures, was similar to germi-

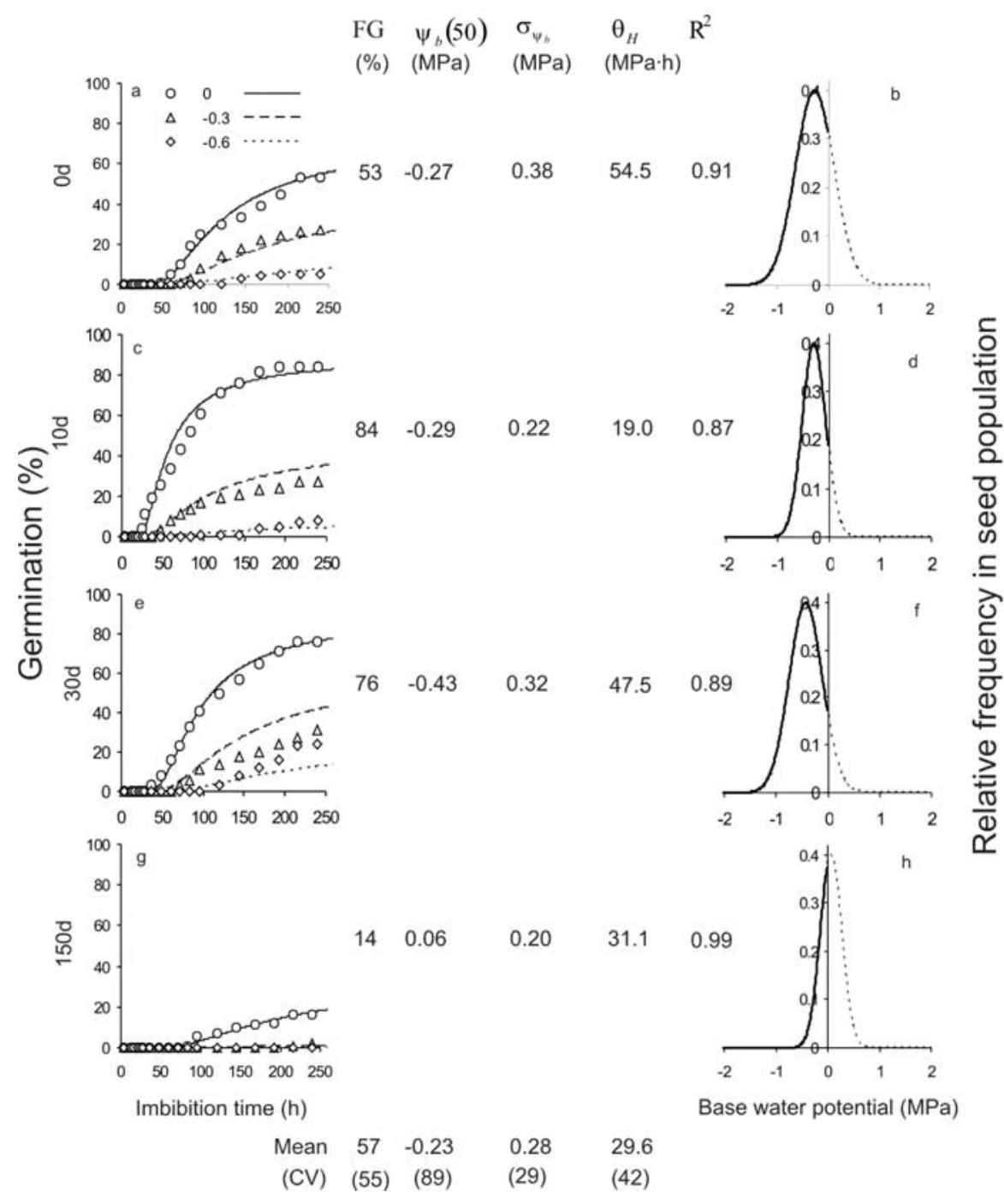

Fig. 3. Germination time courses of Cirsium arvense seeds after burial of $0,10,30$ and 150 days in $19^{\circ} \mathrm{C}$. The symbols, lines and letters as Figure 1. 


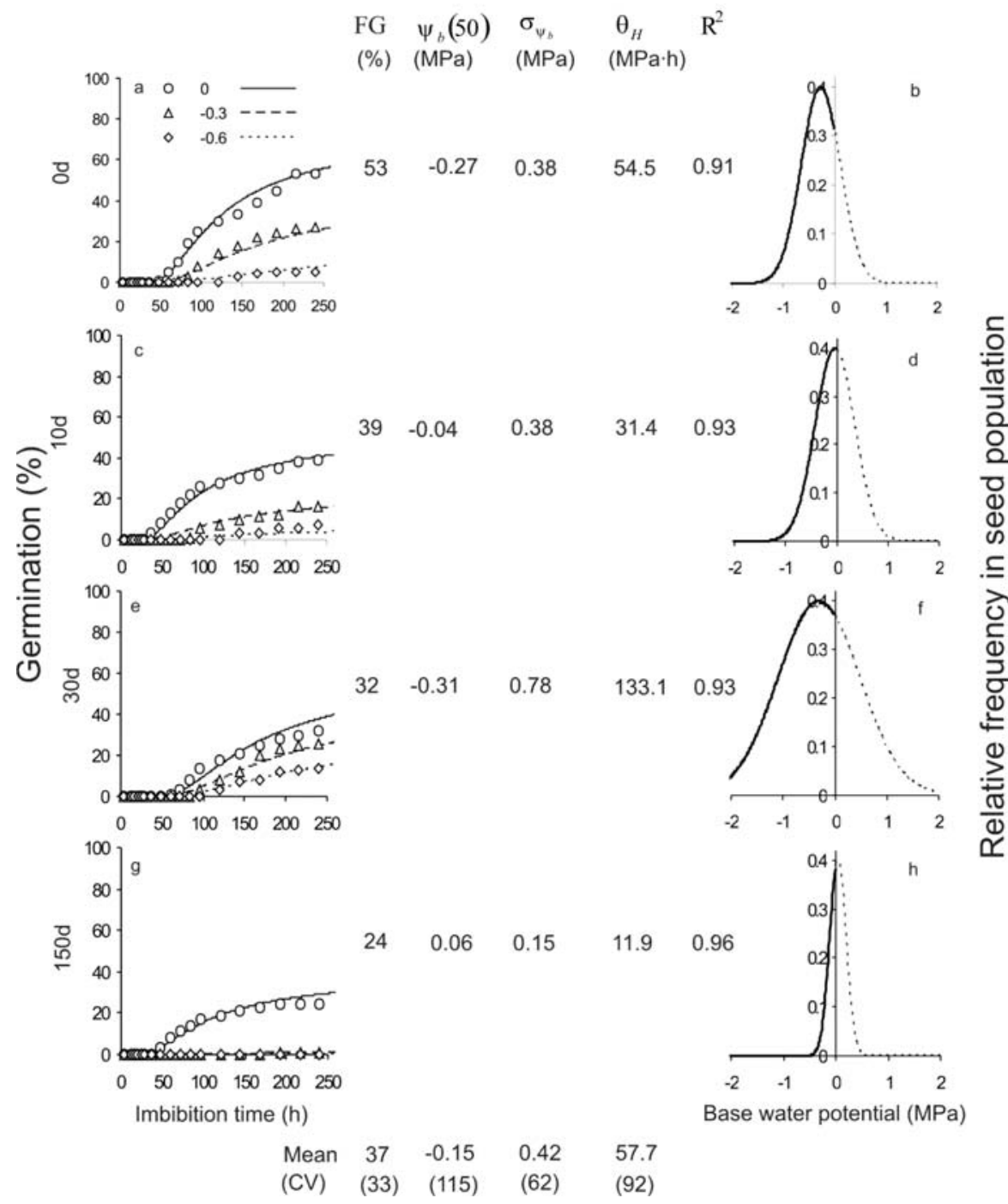

Fig. 4. Germination time courses of Cirsium arvense seeds after burial of $0,10,30$ and 150 days in $26^{\circ} \mathrm{C}$. The symbols, lines and letters as Figure 1.

nation at alternating temperatures (Fig. 9). Fluctuating temperatures with an amplitude of $14^{\circ} \mathrm{C}$ lowered the value of all the three hydrotime model parameters only to a small extent. The fit of experimental data to the hydrotime model was good with $\mathrm{R}^{2}$ of $0.88-0.89$, both at constant and alternating temperatures (Fig. 9).

\section{DISCUSSION}

Temperature is regarded as the main factor regulating changes in seed dormancy level in temperate environments, although there are more and more data which confirm that the effect of temperature on dormancy can be modified by soil humidity (Christensen et al. 1996; Christensen Bauer et al. 1998; Bochenek et al. 2007). Seed dormancy of annual species is usually released or decreased during the season preceding the time suitable for seedling development and growth of plants. At the time preceding the season with conditions unfavourable to the survival of plants, dormancy induction usually takes place (Karssen et al. 1988; Bouwmeester 1990; Baskin and Baskin 1992).

Seeds of summer annual species are dispersed in autumn. During winter dormancy may be partly or completely broken as a result of the effect of low temperature stratification. When soil temperature begins to rise in spring, germi- nation temperature range coincides with the soil temperature, and germination takes place. At high summer temperatures, the seeds which have not germinated develop secondary dormancy (Bouwmeester and Karssen 1992, 1993; Benech-Arnold and Sánchez 1995). Winter annual species show a reverse dormancy pattern in comparison with summer species. After dispersal during spring and early summer, high temperatures lead to seed dormancy break. When soil temperature begins to fall towards the end of summer and in early autumn, the temperature range required for germination coincides with the temperature of the environment, and germination takes place. During winter low soil temperatures may induce secondary dormancy so that germination is limited to late autumn or winter (Baskin and Baskin 1983, 1989). The environmental regulation of seed dormancy in perennial species and those with a varied life cycle (species that can be annuals, biennials or short-lived perennials) has not been well studied yet.

Creeping thistle seeds exhibit nondeep physiological dormancy (PD), typical of most weeds of the Asteraceae family (Baskin and Baskin 2004; Finch-Savage and LeubnerMetzger 2006). A population hydrotime model was used for the study of dormancy changes, which allowed a detailed analysis of subtle dormancy changes based on differences in biologically significant parameter values of the model (Bradford 1995, 1996). The results showed that the pri- 
mary dormancy of achenes was broken only during the first stratification month at moderate temperatures. At $19^{\circ} \mathrm{C}$ this process was faster than at $12^{\circ} \mathrm{C}$. After 10 days at a higher temperature the germination percentage was enhanced due to the fact that this process had been greatly accelerated (lowering of $\theta_{H}$ ) and better synchronised (narrower distribution of base water potential). After 30 days germination increased only as a result of the decrease in seed sensitivity to water stress (shift of $\psi_{b}(50)$ towards more negative values). At $12^{\circ} \mathrm{C}$ after 10 days, the effect of the decreased stress-tolerance was eliminated by a great acceleration of germination. That is why the considerable rise in the germination percentage took place only after 30 days, when the sensitivity to low water potential decreased again. Very long storage of Cirsium arvense achenes in moist soil gave rise to secondary dormancy induction at all the temperatures, mainly as a result of the decrease in waterstress tolerance (the value of the mean base water potential exceeded 0 ).

The fact that the seeds lost their water-stress tolerance to a large extent, which could be seen in the shift of $\psi_{b}(50)$ to positive values, caused a gradual induction of secondary seed dormancy during dry storage at all the temperatures. The high positive value of the mean base water potential meant that most of the seed population could not germinate in any conditions (Bradford 1996, 2002). The increase in the hydrotime value that seeds accumulate in order to germinate was also of importance. A higher $\theta_{H}$ of a seed population was connected with an decrease in germination speed, which resulted in the prolongation of imbibition phase II. It is a well-known fact that dormant seeds can remain in the plateau phase for months and years before completing germination (Powell et al. 1984; Bradford 1995).

The authors studying the environmental regulation of seed dormancy by means of the threshold hydrotime model obtained different results. In the seeds of most species the mean base water potential progressively decreased with storage time, whereas a lower stratification temperature and higher afterripening temperature accelerated dormancy release (Christensen et al. 1996; Christensen Bauer et al. 1998; Meyer et al. 2000; Batlla and Benech-Arnold 2004; Alvarado and Bradford 2005; Bair et al. 2006). Seeds of scentless mayweed, a species with a plastic life strategy, released the primary dormancy at both low and high stratification temperatures, even though at low temperatures the process took place fast and lasted for a short time, and at high temperatures was slow but long. This confirms the data obtained from the study of the seasonal dormancy pattern of this species' achenes stored in a soil seed bank. These data indicate that temperature probably does not play the most important role in dormancy regulation. Mean base
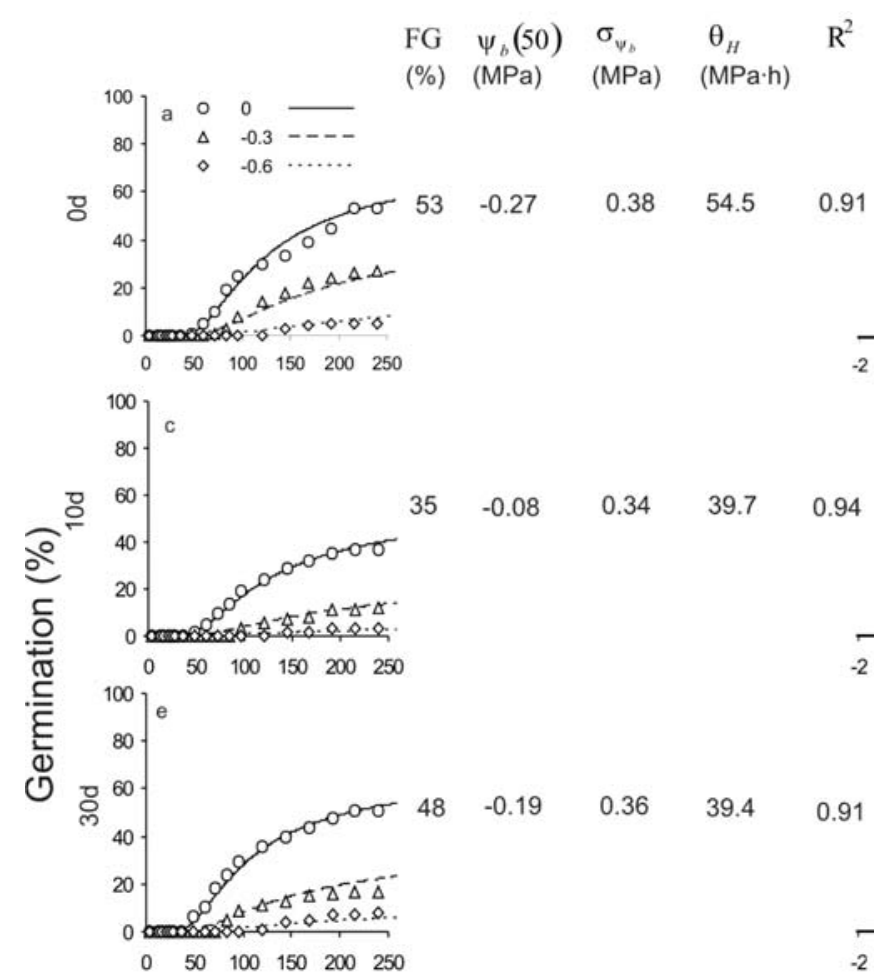

0.38
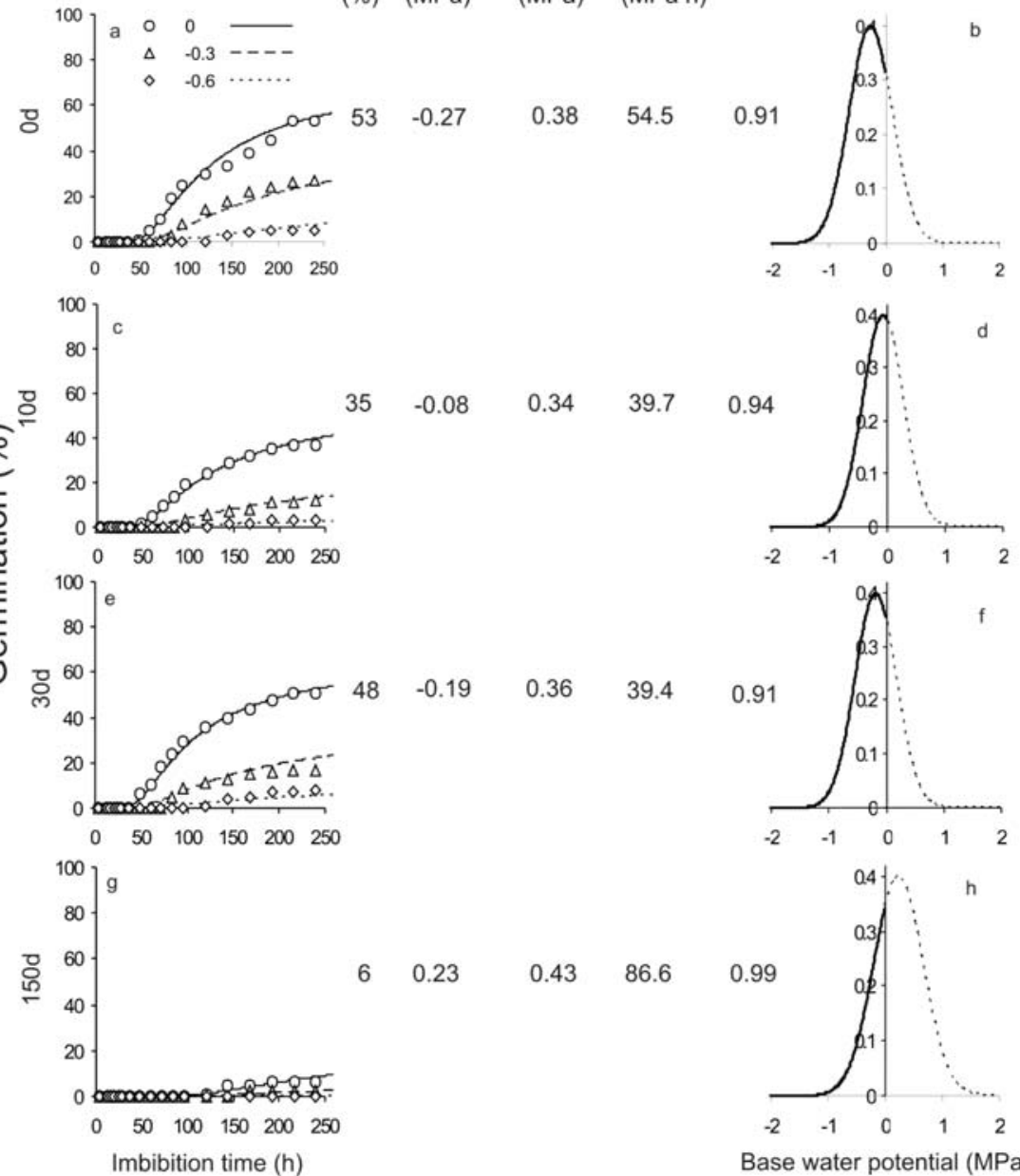

$-0.08$

0.34

39.7

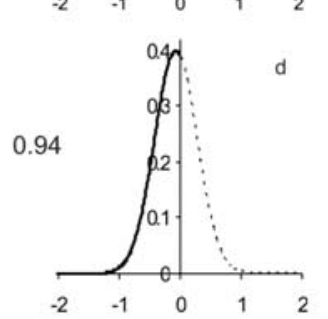

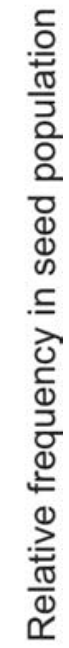

Mean $36 \quad 0.07$
Fig. 5. Germination time courses of Cirsium arvense seeds after dry storage of $0,10,30$ and 150 days in $12^{\circ} \mathrm{C}$. The symbols, lines and letters as Figure 1. 


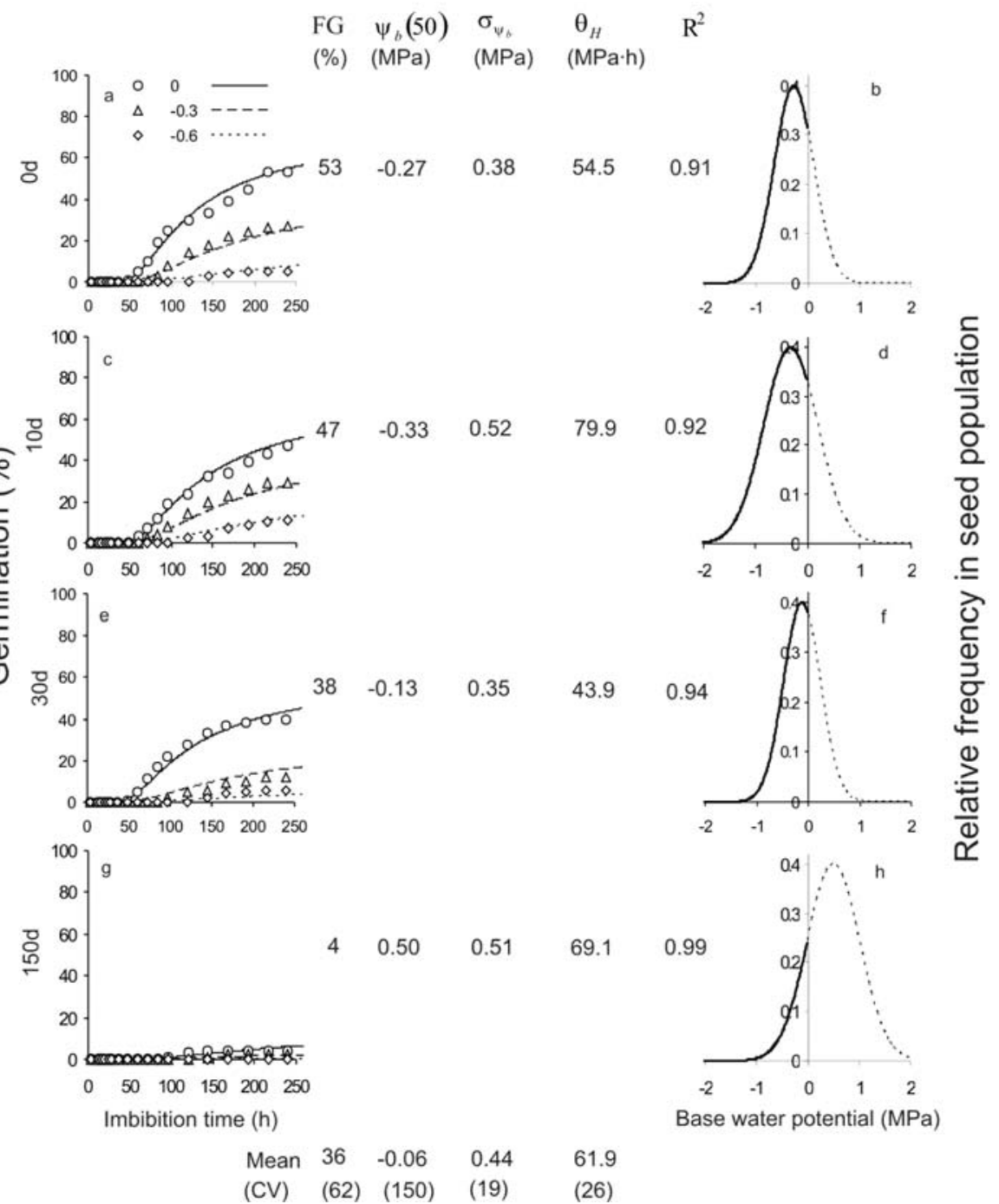

Fig. 6. Germination time courses of Cirsium arvense seeds after dry storage of $0,10,30$ and 150 days in $19^{\circ} \mathrm{C}$. The symbols, lines and letters as Figure 1. water potential values in seeds exhumed each month over a year were related to precipitation. Soil temperature could be a trend-controlling factor of this relationship (Bochenek et al. 2007).

Very high CV values of $\psi_{b}(50)$ and low CV values of the other model parameters for Cirsium arvense seeds confirm Bradford's suggestions $(1995,1996)$ that the mean base water potential can be regarded as the main indicator of dormancy level. Nevertheless, for cornflower and scentless mayweed seeds (species with varied life cycles), as well as for common dandelion seeds (a perennial species), $\psi_{b}(50)$ cannot be considered as the only indicator of dormancy level, since the CVs of the remaining model parameters were of a similar order of magnitude (own non-published data).

Germination of creeping thistle seeds in water potential of $0 \mathrm{MPa}$ was similar at both fluctuating and constant temperature which was the average of extreme temperatures. However, the seeds of many other non-cultivated species completely release their dormancy only after exposure to fluctuating temperatures (Pons 2000; Probert 2000; Kruk and Benech-Arnold 2000; Benech-Arnold et al. 2000; Batlla et al. 2004). It appeared that for Cirsium arvense alternating temperatures did not affect germination, which arose from the lack of visible changes in all the hydrotime model parameters. However, Huarte and Benech-Arnold (2005) and Huarte (2006) reached the conclusion for several other non-cultivated species that even if alternating temperatures did not increase the level of germination, they led to considerable changes in the physiology of germination of this species. For cornflower seeds, an increase in $\theta_{H}$ under fluctuating temperatures offset the more rapid germination speed expected from a reduction in the mean base water potential. Alternating temperatures decreased germination of common dandelion seeds, which resulted mainly from the prolongation of the plateau phase of imbibition (an increase in the value of $\theta_{H}$ ). Scentless mayweed germinated better at a constant temperature than alternating temperatures. Daily temperature fluctuations led to increased sensitivity to water stress, slightly enhancing germination synchrony and rate at the same time (own non-published data). The fact that seeds of the Asteraceae family did not increase their germination under the influence of alternating temperatures was confirmed by far lower germination results for seeds exhumed from the field than for seeds stored in the laboratory at a constant temperature (Bochenek et al. 2006-2008). This may be related to the strategy of persistent soil seedbank formation. A soil seed population would not fully germinate under the influence of fluctuating temperatures if the water potential was even a little lower. This would prevent a part of seed population from germinating so that it could survive in soil until the next seasons. 


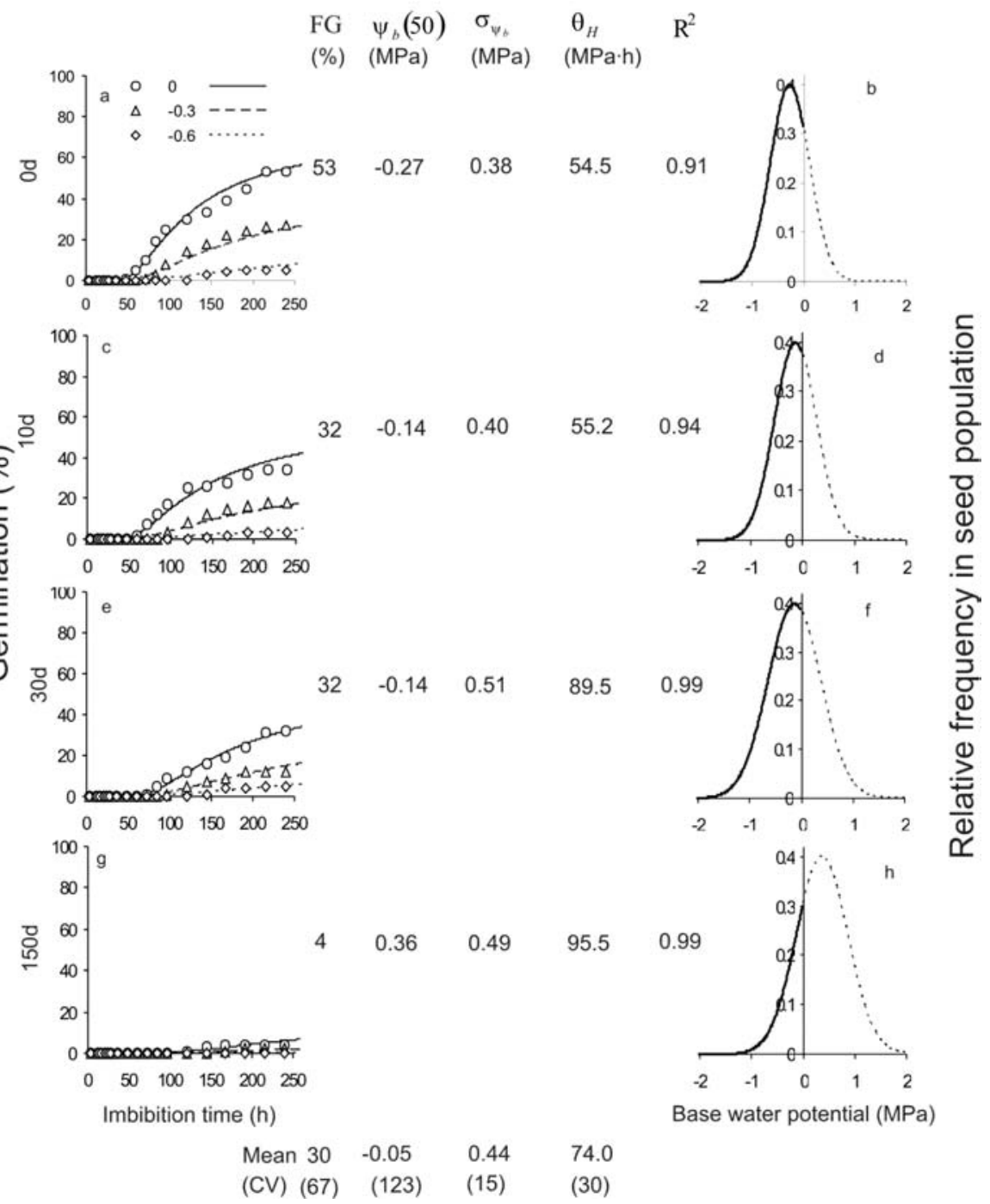

Fig. 7. Germination time courses of Cirsium arvense seeds after dry storage of $0,10,30$ and 150 days in $26^{\circ} \mathrm{C}$. The symbols, lines and letters as Figure 1.

\section{LITERATUTRE CITED}

ALVARADO V., BRADFORD K.J. 2005. Hydrothermal time analysis of seed dormancy in true (botanical) potato seeds. Seed Sci. Res. 15: 77-88.

BAIR B.B., MEYER S.E., ALLEN P.S. 2006. A hydrothermal after-ripening time model for seed dormancy loss in Bromus tectorum L. Seed Sci. Res. 16: 17-28.

BATLLA D., BENECH-ARNOLD R.L. 2004. A predictive model for dormancy loss in Polygonum aviculare L. seeds based on changes in population hydrotime parameters. Seed Sci. Res. 14: 277-286.

BASKIN J.M., BASKIN C.C. 1983. Seasonal changes in the germination responses of buried seeds of Arabidopsis thaliana and ecological interpretation. Bot. Gazette 144: 540-543.

BASKIN J.M., BASKIN C.C. 1989. Physiology of dormancy and germination in relation to seed bank ecology. In: Ecology of soil seed banks. Leck M.A. Parker W.T., Simpson M.I. (eds). Academic Press. London pp. 53-66.

BASKIN J.M., BASKIN C.C. 1992. Role temperature and light in the germination ecology of buried seeds of weed species of distributed forests. I. Lobelia inflata. Can. J. Bot. 70: 589-592.

BASKIN J.M., BASKIN C.C. 2004. A classification system for seed dormancy. Seed Sci. Res. 14: 1-16.

BENECH-ARNOLD R.L., SÁNCHEZ R.A. 1995. Modeling weed seed germination. In: Seed development and germination.
Kigel J., Galili G. (eds). Marcel Dekker, Inc. New York, Basel, Hong Kong, pp. 545-566.

BENECH-ARNOLD R.L., SÁNCHEZ R.A., FORCELLA F. KRUK B.C., GHERSA C.M. 2000. Environmental control of dormancy in weed seed banks in soil. Field Crops Res. 67: 105-122.

BOCHENEK A., GIEŁWANOWSKA I. 2006. Effect of temperature, desiccation, nitrate and light on the seasonal dormancy pattern expression of Cirsium arvense (L.) Scop. achenes. Zesz. Prob. Post. Nauk Rol. 509. 61-74.

BOCHENEK A., GOŁASZEWSKI J., GÓRECKI R.J. 2007. The seasonal dormancy pattern and germination of Matricaria maritima subsp. inodora (L.) Dostal seeds in hydrotime model terms. Acta Soc. Bot. Pol. 76: 299-307.

BOCHENEK A., GIEŁWANOWSKA I., ŻUK-GOŁASZEWSKA K. 2008. Effect of environmental conditions on germination and persistence of Taraxacum officinale seeds in a soil bank. Zesz. Prob. Post. Nauk Rol. 524: 463-476.

BOURDÔT G.W. HURRELL G.A., SAVILLE D.J., LEATHWICK D.M. 2006. Impacts of applied Sclerotinia sclerotiorum on the dynamics of a Cirsium arvense population. Weed Res. 46: 61-72.

BOUWMEESTER H.J. 1990. The effect of environmental conditions on the seasonal dormancy pattern of weed seeds. Ph.D. thesis, Agricultural University in Wageningen, pp. 5-156.

BOUWMEESTER H.J., KARSSEN C.M. 1992. The dual role of temperature in the regulation of the seasonal changes in do- 


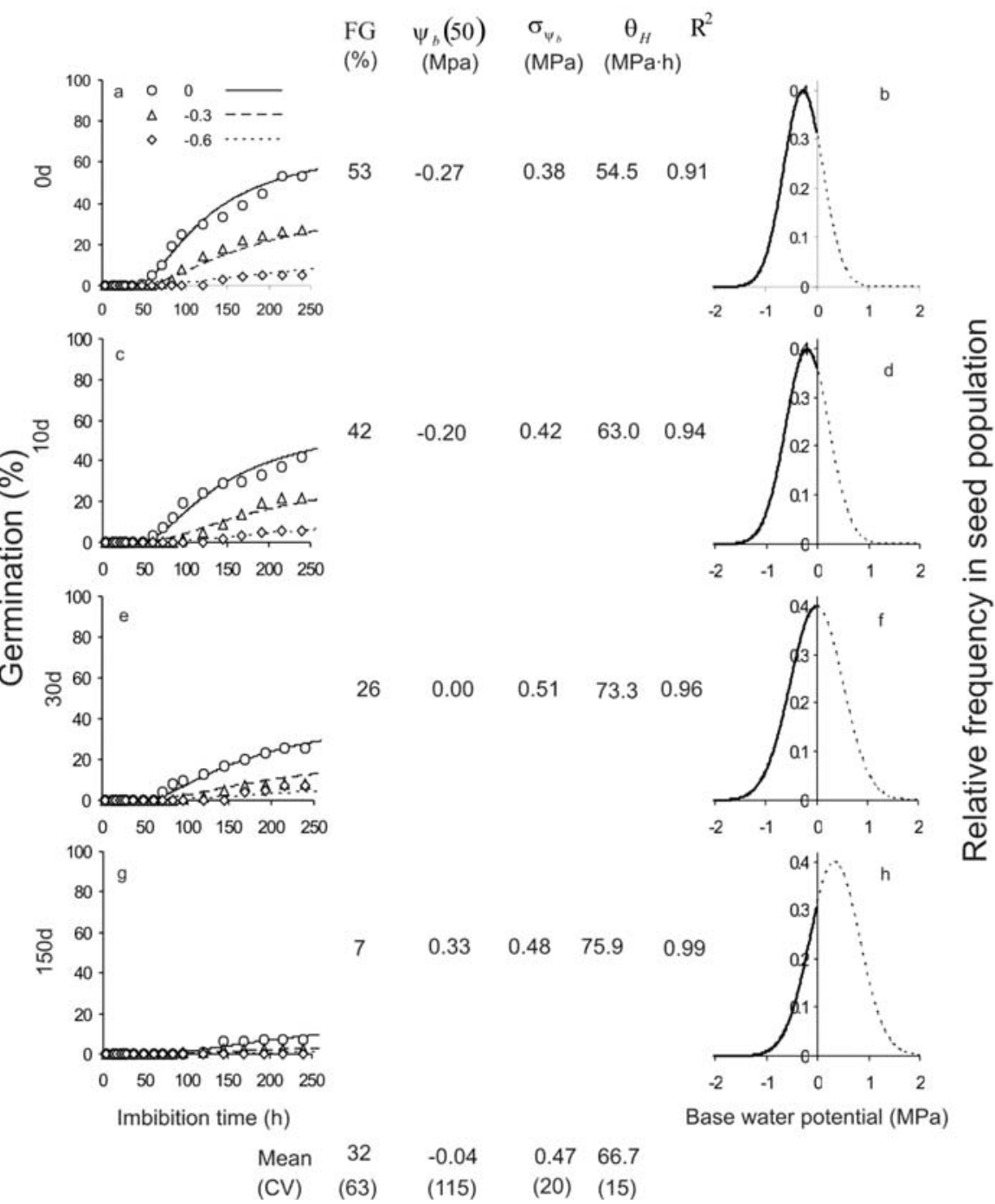

Fig. 8. Germination time courses of Cirsium arvense seeds after dry storage of $0,10,30$ and 150 days in $33^{\circ} \mathrm{C}$. The symbols, lines and letters as Figure 1. rmancy and germination of seeds of Polygonum persicaria L. Oecologia 90: 88-94.

BRADFORD K.J. 1990. A water relation analysis of seed germination rates. Plant Physiol. 94: 840-849.

BRADFORD K.J. 1995. Water relation in seed germination. In: Seed development and germination. Kigel J. and Galili G. (eds). Marcel Dekker, New York, pp. 351-396.

BRADFORD K.J. 1996. Population-based models describing seed dormancy behaviour: implications for experimental design and interpretation. In: Plant dormancy: physiology, biochemistry and molecular biology. Lang G.A. (ed.). CAB International, Wallingford, pp. 313-339.

BRADFORD K.J. 2002. Applications of hydrothermal time to quantifying and modeling seed germination and dormancy. Weed Sci. 50: 248-260.

BRADFORD K.J., SOMASCO O.A. 1994. Water relations of lettuce seed thermoinhibition. I. Priming and endosperm effects on base water potential. Seed Sci. Res. 4: 1-10.

CHRISTENSEN M., MEYER S.E., ALLEN P.S. 1996. A hydrothermal time model of seed after-ripening in Bromus tectorum. Seed Sci. Res. 6: 155-163.

CHRISTENSEN BAUER M., MEYER S.E., ALLEN P.S. 1998. A simulation model to predict seed dormancy loss in the field for Bromus tectorum L. J. Exp. Bot. 49: 1235-1244.

DONALD W.W. 1990. Management and control of Canada thistle (Cirsium arvense). Rev. Weed Sci. 5: 193-249.

EDWARDS G.R., BOURDOT G.W., CRAWLEY M.J. 2000. Influence of herbivory, competition and soil fertility on the abundance of Cirsium arvense in acid grassland. J. App. Ecol. 37: 321-334.

FINCH-SAVAGE W.E., LEUBNER-METZGER G. 2006. Seed dormancy and the control of germination. New Phytol. 171: $501-52$

FRIEDLI J., BACHER S. 2001. Direct and indirect effects of $\mathrm{s}$ shoot-base boring weevil and plant competition on the performance of creeping thistle, Cirsium arvense. Biol. Control 22: 219-226.

GOŁASZEWSKI J., BOCHENEK A. 2008. A computational procedure for hydrotime concept of seed germination. Biom. Let. 45: 55-67.

GRAGLIA E., MELANDER B., JENSEN R.K. 2006. Mechanical and cultural strategies to control Cirsium arvense in organic arable cropping systems. Weed Res. 46: 304-312.

GUMMERSON R.J. 1986. The effect of constant temperatures and osmotic potential on the germination of sugar beet. J. Exp. Bot. 37: 729-741.

GUSKE S., SCHULZ B., BOYLE C. 2004. Biocontrol options for Cirsium arvense with indigenous fungal pathogens. Weed Res. 44: 107-116.

HEIMANN B., CUSSANS G.W. 1996. The importance of seeds and sexual reproduction in the population biology of Cirsium arvense - a literature review. Weed Res. 36: 495-503.

HETTWER U., GEROWITT B. 2004. An investigation of genetic variation in Cirsium arvense field patches. Weed Res. 44: 289$-297$ 


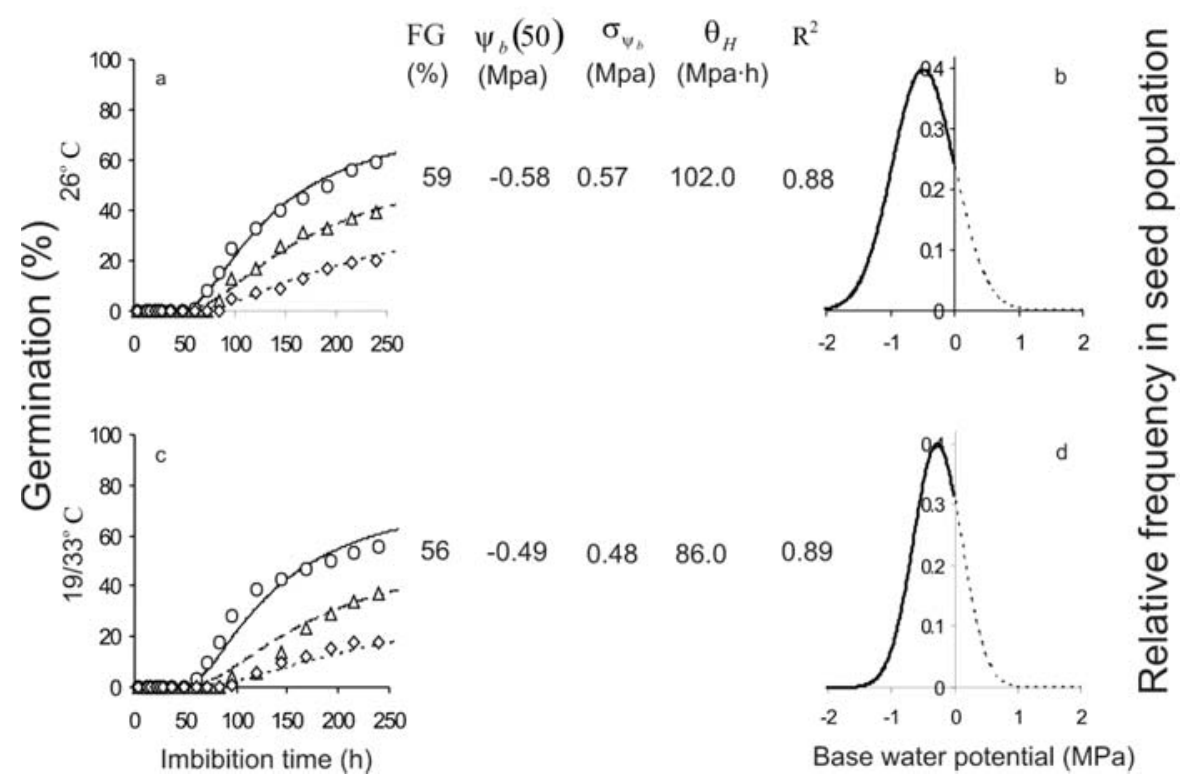

Fig. 9. Germination time courses of Cirsium arvense seeds at constant temperature of $26^{\circ} \mathrm{C}$ and fluctuating temperatures of $19 / 33^{\circ} \mathrm{C}, 12 / 12 \mathrm{~h}$. The symbols and lines as Figure 1. a, c-germination time courses at ranges of water potentials. $b, d-$ normal distribution showing the relative frequencies of $\psi_{b}(50)$ values.
HUARTE R. 2006. Hydrotime analysis of the effect of fluctuating temperatures on seed germination in several non-cultivated species. Seed Sci. Technol. 34: 533-547.

HUARTE R., BENECH-ARNOLD R.L. 2005. Incubation under fluctuating temperatures reduces mean base water potential for seed germination in several non-cultivated species. Seed Sci. Res. 15: 89-97.

JUMP A.S., WOODWARD F.I., BURKE T. 2003. Cirsium species show disparity in patterns of genetic variations at their range-edge, despite similar patterns of reproduction and isolation. New Phytol. 160: 359-370.

KARSSEN C.M., DERKX P.M., POST B.J. 1988. Study of seasonal variation in dormancy of Spergula arvensis L. seeds in a condensed annual temperature cycle. Weed Res. 28: 449-457.

KRUK B.C., BENECH-ARNOLD R.L. 2000. Evaluation of dormancy and germination responses to temperature in Carduus acanthoides and Anagallis arvensis using a screening system, and relationship with field-observed emergence patterns. Seed Sci. Res. 10: 77-88.

KUMAR V., IRVINE D.E.G. 1971. Germination of seeds of Cirsium arnense (L.) Scop. Weed Res. 11: 200-203.

LARSEN S.U., BAILlY C., CÔME D., CORBINEAU F. 2004. Use of the hydrothermal time model to analyse interacting effects of water and temperature on germination of three grass species. Seed Sci. Res. 14: 35-50.

MEYER S.E., DEBAENE-GILL S.B., ALLEN P.S. 2000. Using hydrothermal time concepts to model seed germination response to temperature, dormancy loss and priming effects in Elymus elymoides. Seed Sci. Res. 10: 213-223.
MICHEL B.E. 1983. Evaluation of the water potentials of solutions of the polyethylene glycol 8000 both in the absence and presence other solutes. Plant Physiol. 72: 66-70.

PONS T.L. 2000. Seed responses to light. In: Seeds - the ecology in plant communities. Fenner M. (ed.). CAB International, Wallingford, pp. 237-260.

PROBERT R.J. 2000. The role of temperature in regulation of seed dormancy and germination. In: Seeds - the ecology in plant communities. Fenner M. (ed.). CAB International, Wallingford, pp. 261-292.

SKINNER K., SMITH L., RICE P. 2000. Using noxious weed lists to prioritize targets for developing weed management strategies. Weed Sci. 48: 640-644.

TOSELLI M.E., CASENAVE E.C. 2002. The hydrotime model analysis of cottonseed germination as tool in priming. Seed Sci. Technol. 30: 549-557.

TOSELLI M.E., CASENAVE E.C. 2005. Hydropriming and cottonseed germination under unfavorable conditions: modifications in hydrotime parameters. Seed Sci. Technol. 33: 87-96.

WANG R., BAI Y., TANINO K. 2005. Germination of winterfat (Eurotia lanata (Pursh) Moq.) seeds at reduced water potentials: testing assumptions of hydrothermal time model. Environ. Exp. Bot. 53: 49-63.

ŻUK-GOŁASZEWSKA K., BOCHENEK A., GOŁASZEWSKI J. 2007. Effect of scarification on seed germination of red clover in hydrotime model terms. Seed Sci. Technol. 35: 326-336. 